\title{
An elusive cause of pleural effusion
}

\author{
Manish K Saha, Tarek Hamieh \\ Department of Internal Medicine, Health Partners, Saint Paul, Minnesota, USA \\ Correspondence to Dr Manish K Saha, drmks1@gmail.com
}

\begin{abstract}
Summary
A 32-year-old man was admitted with cerebrospinal fluid leakage from a right scalp surgical wound after a resection of recurrent meningioma and reconstruction of skull with muscle flap 3 weeks earlier. On day 4 of admission, he was found to be tachycardic and decreased breath sounds on the right side. Chest $x$-ray revealed a large right pleural effusion which was found to be exudative after thoracocentesis. Infectious work-up and cytology was negative. CT showed both parietal and visceral pleural masses, which was consistent with meningioma on ultrasound-guided biopsy. He underwent right-side decortication and pleurodesis for recurrent pleural effusion. He declined further treatment and opted for hospice care and expired a month later.
\end{abstract}

\section{BACKGROUND}

Meningiomas are usually benign but sometimes atypical meningioma has a metastatic potential. Exudative pleural effusion as a manifestation of metastatic intracranial meningioma is rare.

\section{CASE PRESENTATION}

A 32-year-old man was admitted with cerebrospinal fluid (CSF) leakage from a right scalp surgical wound after a resection of recurrent meningioma and reconstruction of skull with muscle flap 3 weeks earlier. His medical history was significant for acute lymphoblastic lymphoma at age 3 for which he underwent cranial radiation. He was diagnosed with meningioma, 6 years prior to this presentation. He has had multiple resections, cyberknife therapies and various chemotherapy treatments for recurrences of intracranial meningioma. Medicine consultation was requested for tachycardia on day 4 since admission.

The patient had no chest pain, cough, fever or shortness of breath. His blood pressure was $110 / 50 \mathrm{~mm} \mathrm{Hg}$, pulse of $110 / \mathrm{min}$, regular, with oxygen saturation of $93 \%$ on room air. Physical examination revealed decreased breath sounds on the right side. There was no evidence of peripheral oedema or calves tenderness.

\section{INVESTIGATIONS}

Initial haemogram and serum chemistry were normal. ECG revealed sinus tachycardia, while chest x-ray was notable for a large right pleural effusion (figure 1). Ultrasound duplex of lower extremities was normal. The pleural effusion was new and was not evident on a previous chest x-ray performed 3 weeks earlier. A litre of straw colour fluid was drained through a thoracocentesis. Pleural fluid was remarkable for 319 nucleated cells/ $\mu$ l with $63 \%$ polymorphonuclear leucocytes, lactate dehydrogenase of $2530 \mu / 1$ and total protein of $3.4 \mathrm{~g} / \mathrm{dl}$ suggestive of an exudative effusion. Pleural fluid gram stain and cultures were non-revealing and cytology was negative for malignant cells. A CT of the chest was done for further evaluation of rapidly reaccumulating pleural effusion. In addition to a large right pleural effusion with atelectasis, a confluent mass involving both parietal and visceral pleura was seen (figure 2). There were no lung masses other than an indeterminate $(2.8 \times 5 \mathrm{~mm})$ left upper lobe nodule. Ultrasound-guided biopsy of the pleural mass was consistent with meningioma with 5-15 mitoses/10 highpower field (hpf) (WHO grade 2; figures 3 and 4).

\section{TREATMENT}

Incidentally found meningiomas that are asymptomatic and small can usually be followed up clinically and with serial imaging studies. Alternatively, symptomatic or enlarging meningiomas warrant surgical resection if feasible. When complete resection is achievable and histology is consistent with WHO grade 1 , adjuvant radiation therapy (RT) is not indicated. RT is indicated when a complete resection cannot be performed without causing significant neurological deficits due to its location. ${ }^{1}$ Atypical meningiomas (WHO grades 2 and 3) have a higher chance of recurrence even after complete surgical

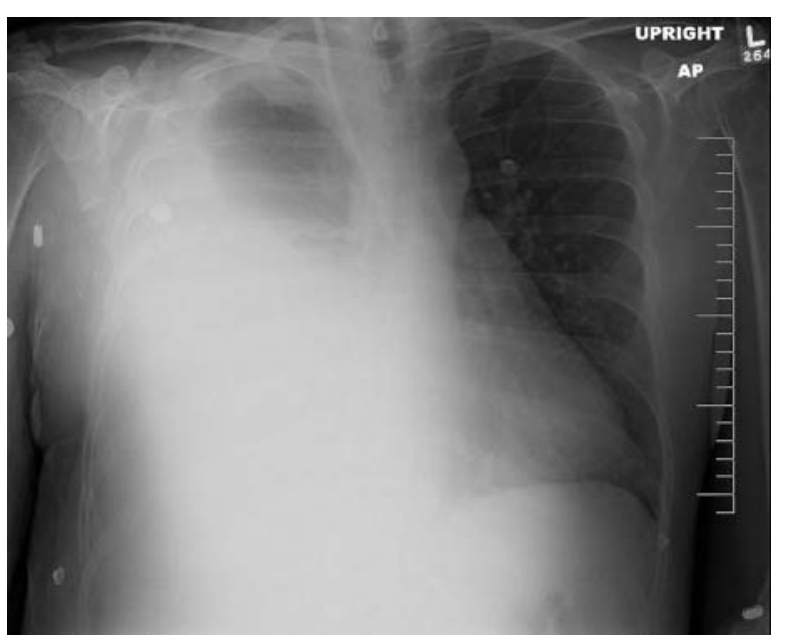

Figure 1 Chest x-ray showing large right pleural effusion. 


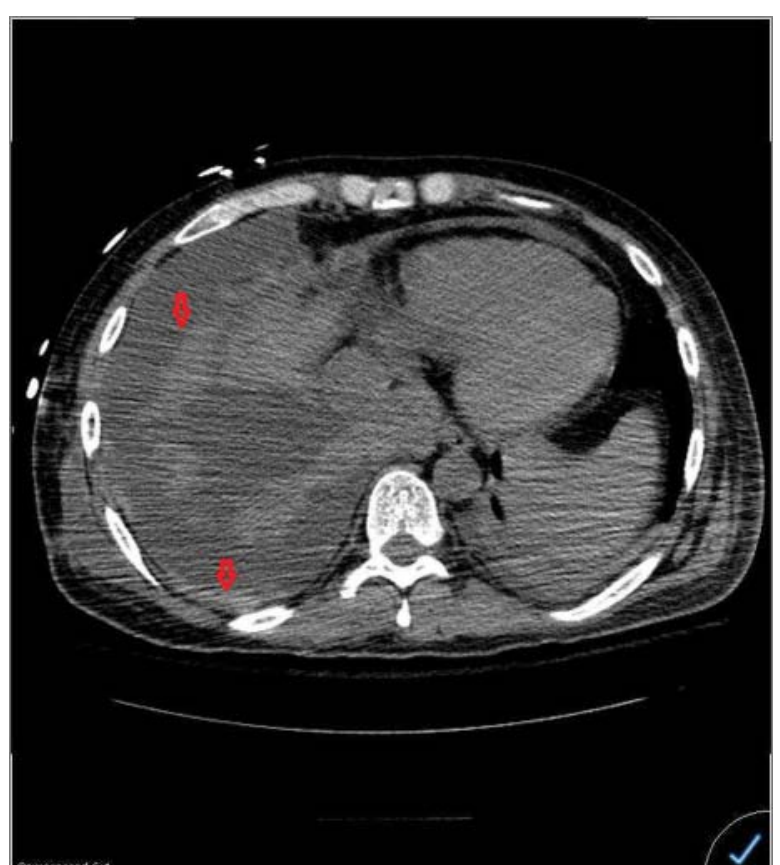

Figure 2 CT of chest showing parietal (lower arrowhead) and visceral (upper arrowhead) pleural soft tissue mass.

resection and therefore adjuvant RT may be indicated. ${ }^{2}{ }^{3}$ When tumours are located close to important neurological structures and surgery may result in significant neurological deficits then stereotactic radiosurgery and stereotactic radiotherapy may be helpful.

Atypical meningiomas may recur even after surgical resection and adjuvant radiotherapy. In this subset of patients, additional chemotherapy may be tried although there is no consensus on the regimen. Inhibitor of growth factors, angiogenesis and hormonal influences are being studied using different regimen in separate clinical trials. Imatinib (inhibitor of platelet-derived growth factor), bevacizumab (inhibitor of vascular endothelial growth factor and therefore angiogenesis), somatostatin analogues are being studied. ${ }^{1}$ Travitzky et al ${ }^{4}$ described a case where they had success with doxil (pegylated liposomal form of doxorubicin) in the treatment of pleuropulmonary metastases from a cranial meningioma.

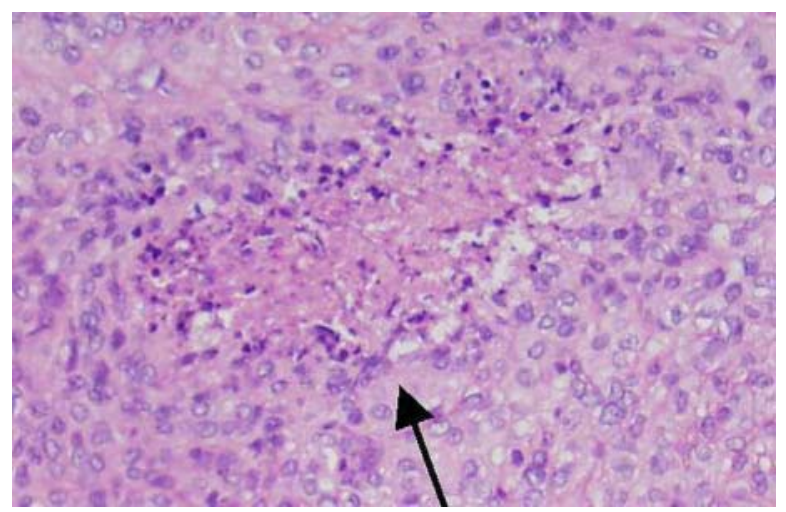

Figure 3 Histology of pleural mass showing mitoses.

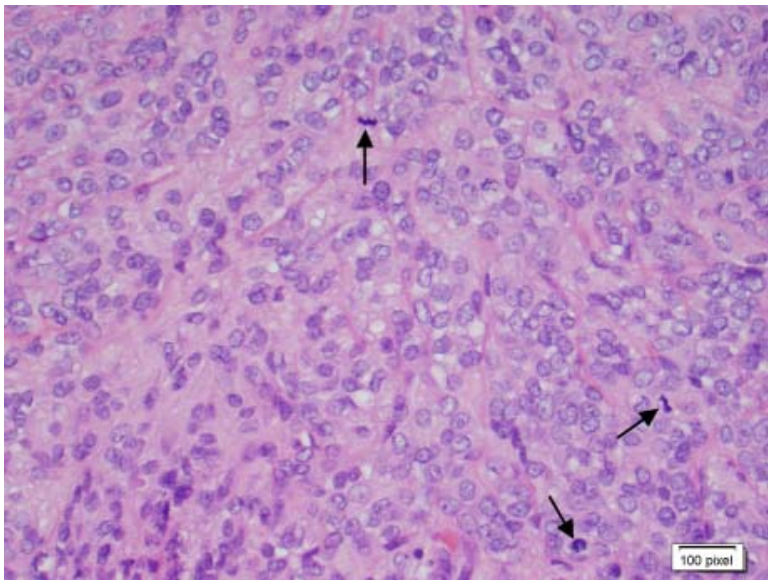

Figure 4 Histology of pleural mass showing necrosis.

\section{OUTCOME AND FOLLOW-UP}

Since the initial diagnosis of intracranial meningioma, the patient had failed multiple chemotherapy regimens including temozolomide, sorafenib, for his recurrent aggressive tumour. During this admission, the patient's hospital course was however complicated by acute renal failure, secondary to non-steroidal anti-inflammatory drugs, requiring haemodialysis. Due to renal insufficiency and recent surgical scalp wound, the patient was not felt to be a candidate for further chemotherapy treatment with monoclonal antibody such as bevacizumab, an inhibitor of vascular endothelial growth factor. Given the rapid reaccumulation of his pleural effusion, patient underwent decortication of his lung and talc pleurodesis. The patient had declined further chemotherapy and opted for hospice care and expired a month later.

\section{DISCUSSION}

Meningiomas are tumours arising from arachnoid cells, usually benign, and mainly located in the central nervous system. They are typically slow-growing tumours and are thus 'perceived' as benign. Metastatic meningiomas have been reported as low as $0.1 \% .^{5}$ The most common site of metastatic spread is lung followed by abdominal viscera, lymph node and bones. ${ }^{56}$ Exudative pleural effusion as a primary manifestation of metastatic intracranial meningioma has rarely been reported. ${ }^{78}$

Intracranial radiation has been associated with a fourfold increase in the development of meningioma. ${ }^{9}$ Our patient was diagnosed with symptomatic meningioma at the age of 26 ( 23 years after been exposed to radiation). Rubinstein $e t a l^{9}$, in their analysis of 201 patients, found that meningiomas arising as a result of exposure to intracranial radiation are usually located in the parafalcine/ vertex area rather than at the skull bases similar to our patient. Whether meningiomas related to radiation are associated with higher risk of metastatic spread is unclear. Manipulation of meningiomas (from multiple surgeries for recurrence), venous sinus invasion, WHO grade 2 (atypical) or 3 (anaplastic) histology, have higher predilection for metastatic spread. ${ }^{10} 11$ WHO grade 2 are histologically atypical and have $\geq 4$ mitotic cells $/ 10 \mathrm{hpf}$, whereas WHO grade 3 have $\geq 20$ mitotic cells $/ 10$ hpf with cytological evidence of malignancy. ${ }^{12}$ Meningiomas may 
metastasise through various routes: haematogenous, lymphatic and direct extension. There have also been reports of metastatic spread via CSF pathways. ${ }^{13}$ In patients with aggressive meningiomas, manipulation of tumour during surgery and invasion of venous sinuses, haematogenous spread is common.

Although primary pulmonary meningiomas arising from ectopic arachnoid cells in the lung have been reported, our patient's atypical features on histology coupled with the aggressive nature of his meningioma requiring numerous surgical interventions probably led to the haematogenous metastatic spread to the pleural cavity. ${ }^{14} 15$

Given our patient's history of atypical (WHO grade 2) intracranial meningioma and unexplained exudative pleural effusion, cytology on pleural fluid was analysed twice with no yield. CT of chest showed predominant extensive pleural (visceral> parietal) masses. Despite this widespread pleural involvement, pleural fluid cytology was unrevealing. Ultrasound-guided biopsy of the pleural masses was consistent with metastatic meningioma (WHO grade 2).

\section{Learning points}

Although uncommon, physicians should be aware of the metastatic potential of intracranial meningioma, especially in the setting of recurrent meningioma or WHO grade 2 or 3 histology.

Competing interests None.

Patient consent Obtained.

\section{REFERENCES}

1. Norden AD, Drappatz J, Wen PY. Advances in meningioma therapy. Curr Neurol Neurosci Rep 2009;9:231-40. Review.

2. Dziuk TW, Woo S, Butler EB, et al. Malignant meningioma: an indication for initial aggressive surgery and adjuvant radiotherapy. J Neurooncol 1998;37:177-88.

3. Aghi MK, Carter BS, Cosgrove GR, et al. Longterm recurrence rates of atypical meningiomas after gross total resection with or without postoperative adjuvant radiation. Neurosurgery 2009;64:56-60.

4. Travitzky M, Libson E, Nemirovsky I, et al. Doxil-induced regression of pleuro-pulmonary metastases in a patient with malignant meningioma Anticancer Drugs 2003;14:247-50.

5. Adlakha A, Rao K, Adlakha $\mathrm{H}$, et al. Meningioma metastatic to the lung. Mayo Clin Proc 1999;74:1129-33. Review.

6. Karasick JL, Mullan SF. A survey of metastatic meningiomas. J Neurosurg 1974;40:206-12.

7. Erman T, Hanta I, Haciyakupoğlu S, et al. Huge bilateral pulmonary and pleural metastasis from intracranial meningioma: a case report and review of the literature. J Neurooncol 2005; 74:179-81.

8. Kaminski JM, Movsas B, King E, et al. Metastatic meningioma to the lung with multiple pleural metastases. Am J Clin Oncol 2001;24:579-82.

9. Rubinstein AB, Shalit MN, Cohen ML, et al. Radiation-induced cerebral meningioma: a recognizable entity. Neurosurgery 1984;61:966-71.

10. Ueyama Y, Morita K, Ochiai $C$, et al. Xenotransplantation of a human meningioma and its lung metastasis in nude mice. $\mathrm{Br} \mathrm{J}$ Cancer 1978; 37:644-7.

11. Taieb G, Campello C, Renard D, et al. Multifocal extracranial meningioma metastases. Arch Neurol 2011:68:388-9.

12. Mawrin C, Perry A. Pathological classification and molecular genetics of meningiomas. J Neurooncol 2010;99:379-91. Review.

13. Ramakrishnamurthy TV, Murty AV, Purohit AK, et al. Benign meningioma metastasizing through CSF pathways: a case report and review of literature. Neurol India 2002;50:326-9. Review.

14. Satoh Y, Ishikawa Y. Primary pulmonary meningioma: ten-year follow-up findings for a multiple case, implying a benign biological nature. J Thorac Cardiovasc Surg 2010;139:e39-40.

15. Izumi N, Nishiyama N, Iwata T, et al. Primary pulmonary meningioma presenting with hemoptysis on exertion. Ann Thorac Surg 2009;88 647-8.

This pdf has been created automatically from the final edited text and images.

Copyright 2012 BMJ Publishing Group. All rights reserved. For permission to reuse any of this content visit http://group.bmj.com/group/rights-licensing/permissions.

BMJ Case Report Fellows may re-use this article for personal use and teaching without any further permission.

Please cite this article as follows (you will need to access the article online to obtain the date of publication).

Saha MK, Hamieh T. An elusive cause of pleural effusion. BMJ Case Reports 2012;10.1136/bcr-01-2012-5616, Published XXX

Become a Fellow of BMJ Case Reports today and you can:

- Submit as many cases as you like

- Enjoy fast sympathetic peer review and rapid publication of accepted articles

- Access all the published articles

- Re-use any of the published material for personal use and teaching without further permission

For information on Institutional Fellowships contact consortiasales@bmjgroup.com

Visit casereports.bmj.com for more articles like this and to become a Fellow 